\title{
Survivin As an Immunohistochemical Prognostic Biomarker in Colorectal Cancer: A Meta-Analysis
}

\author{
(1) Sedef Hande AKTAŞ, ${ }^{1,2,3}$ (1) Büşra EMIR, ${ }^{4}$ (i) Dilara Fatma AKIN BALI, ${ }^{5}$ (i) Ozan YAZICI ${ }^{6}$ \\ ${ }^{1}$ Eskisehir Osmangazi University, Translational Medicine Research and Clinical Center, Eskisehir-Turkey \\ ${ }^{2}$ Department of Biotechnology and Biosafety, Eskisehir Osmangazi University, Graduate Faculty of Natural and Applied Science, \\ Eskisehir-Turkey \\ ${ }^{3}$ Department of Medical Services and Techniques, Eskisehir Osmangazi University, Vocational School of Health Services, Eskisehir-Turkey \\ ${ }^{4}$ Department of Biostatistics, Izmir Katip Celebi University Faculty of Medicine, Izmir-Turkey \\ ${ }^{5}$ Department of Medical Biology, Nigde Omer Halisdemir University Faculty of Medicine, Nigde-Turkey \\ ${ }^{6}$ Department of Medical Oncology, Gazi University Faculty of Medicine, Ankara-Turkey
}

\section{OBJECTIVE}

Genome-level research qualifies survivin as the fourth-best "transcriptome" for colon, lung, brain, breast, and melanoma cancers. To date, it has been stated as a prognostic marker and therapeutic target in colorectal cancer (CRC). However, researchers on survivin expression in CRC are heterogeneous. Our current study aimed to reveal prognostic importance of survivin by investigating all CRC articles up to January 2021 that have performed analysis of survivin by immunohistochemical staining method.

\section{METHODS}

A comprehensive literature search for relevant studies published up to January 2021 was performed using SCOPUS and Pubmed databases. Only articles in which survivin was detected by IHC staining were included in the study. All analyses were conducted by using Comprehensive Meta-Analysis. Eight articles and data of 1535 patients were included in the study. The Hazard Ratio was used to examine the relationship between CRC and survivin protein, for the relative weights of each research article. HR and 95\% confidence interval values and general summary HR were calculated and forest plot graph was obtained.

\section{RESULTS}

Statistical heterogeneity Cochrane's Q test statistics 24.156; $\mathrm{p}=0.004$ and $\mathrm{I}^{2}$ value was obtained as 62,742 . In line with the assumption that the data consisted of different populations, the HR and 95\% CI values were calculated as 1.446 (1.103-1.897) using the Dersimonian and Laird random effects model. In order to evaluate the risk of publication bias, funnel plots were obtained, including log HR and standard error values on the $\mathrm{x}$ and $\mathrm{y}$ axes, respectively.

\section{CONCLUSION}

The analyzes obtained suggest that survivin overexpression in CRC is associated with poor prognosis. (HR=1.446; 95\% CI: 1.103-1.897).

Keywords: BIRC5; colorectal cancer; forest plot; metaanalysis; prognostic; survivin. Copyright $\odot$ 2022, Turkish Society for Radiation Oncology

Dr. Sedef Hande AKTAŞ

Eskişehir Osmangazi Üniversitesi,

Translasyonel Tıp Araştırma ve Klinik Merkezi;

Eskişehir Osmangazi Üniversitesi,

Fen Bilimleri Enstitüsü,

Biyoteknoloji ve Biyogüvenlik Bölümü;

Eskişehir Osmangazi Üniversitesi,

Sağlık Hizmetleri Meslek Yüksekokulu,

Tıbbi Hizmetler ve Teknikler Bölümü,

Eskisehir-Turkey

E-mail: sedefhande@gmail.com 


\section{Introduction}

Colorectal cancer (CRC) is the third most common type of cancer in men and the second most common type of cancer in women.[1] Surgery is the primary method of treatment and provides a high cure rate when the disease is localized. In patients with CRC chemotherapy is used as adjuvant or palliative treatment. The systemic chemotherapy regimen is mainly based on the use of fluoropyrimidines. Drugs such as irinotecan and oxaliplatin are used in combination with fluoropyrimidines which increase response rates, time to progression, and overall survival.[2] However, postoperative recurrence and metastasis are common conditions in CRC and are often associated with poor prognosis and overall survival. In the case of metastasis, the 5-year survival rate of CRC is expressed as $14 \% .[1,2]$

Survivin/BIRC5 is one of the first inhibitors of apoptosis protein (IAPs) family to stimulate apoptosis. The survivin gene, which consists of 3 introns and 4 exons in humans, is located in the 17q25 region of the chromosome and is $14.7 \mathrm{~kb}$ in length. It encodes the survivin protein which is 142 amino acids long and $16.5 \mathrm{KD}$ weigh.[3,4] It is expressed in high amounts in embryonic and fetal organs, but not in most normally differentiated tissues. It is also known to be highly expressed in most cancer types. $[5,6]$ This makes survivin a unique candidate for cancer research. Studies conducted to date have shown a dramatic increase in survivin in the lung, breast, colon, stomach, esophagus, pancreas, bladder, uterus, ovary, large cell non-Hodgkin lymphoma, leukemia, neuroblastoma, melanoma, and non-melanoma skin cancers when compared to normal tissues. [7] Furthermore, genome-level research qualifies survivin as the fourth-best "transcriptome" for colon, lung, brain, breast, and melanoma cancers. On the other hand, it is stated that survivin is not only effective in distinguishing between CRC patients and healthy individuals but also that its high expression causes poor prognosis. However, its expression was accepted as an unfavorable prognostic indicator in esophageal and lung cancer, in addition to that it may have prognostic value in breast, colorectal, pancreatic ductal adenocarcinoma, and hepatic carcinoma.[8]

Prognostic biomarkers identify patients who are probabilistically at either higher risk for adverse disease-related events or a faster rate of decline in their health status.[9] An ideal biomarker is expected to be easily detectable, highly specific, reproducible, preferably noninvasive, and inexpensive.[10] "Survivin," an important protein family member known as IAPs that regulates apoptosis, appears to meet these criteria with (1) expressed in high amounts in most cancer types while it is not expressed in most of the normal differentiated tissues, (2) reacquired from routine biopsy/surgical samples taken from patients (3) relatively inexpensive in use diagnosed immunohistochemically. To date, it has been stated as prognostic marker and therapeutic target in CRC. However, researchs on survivin expression in CRC are heterogeneous. Our current study aimed to reveal its prognostic importance by investigating all CRC research articles to date that have performed analysis of survivin immunohistochemically.

\section{Materials and Methods}

\section{Literature Search}

For this purpose, a search was carried out with relevant keywords from SCOPUS and PUBMED database (up to January 2021); for title-summary-key "IMMUNOHISTOCHEMISTRY" and "SURVIVIN" or "BIRC5" and "COLORECTAL CANCER" and "PATIENT" and for limitation type of document, "ar" and for language: english was entered (https://pubmed. ncbi.nlm.nih.gov/; https://www.scopus.com/). In addition, to search the existing meta-analysis studies analyzing the prognostic value of survivin in CRC a searched was performed from SCOPUS, PUBMED databases with the keywords "SURVIVIN" or "BIRC5" and "COLORECTAL CANCER" and "METAANALYSIS" and only 1 relevant article was found although the article was not related with our research.[11] Besides, a search with "Google Search" tool was performed with the keywords "SURVIVIN" or "BIRC5" and "COLORECTAL CANCER" and "METAANALYSIS" and Huang et al.[12] article has been obtained. The study found in "Google Search" is also available in Pubmed. Thus, three articles whose initial search results were neglected by SCOPUS and PUBMED databases were included in our meta-analysis.

Total, 53 articles from Pubmed database and nine articles from Scopus database were obtained. Twentyfive articles were remained after reduction as can be shown in Table 1 and detailed reduction reasons can be seen in Appendix 1. Finally, eight articles were selected for meta-analysis. Presentation of the procedure of literature searching and selection with numbers of articles at each stage (Fig. 1). 


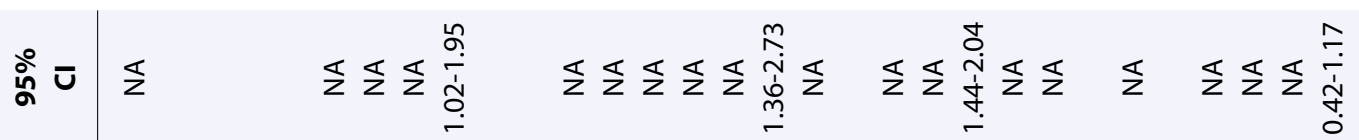

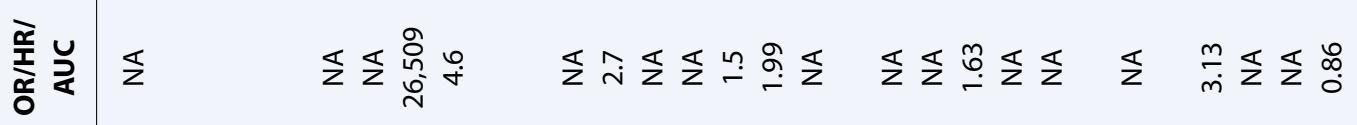

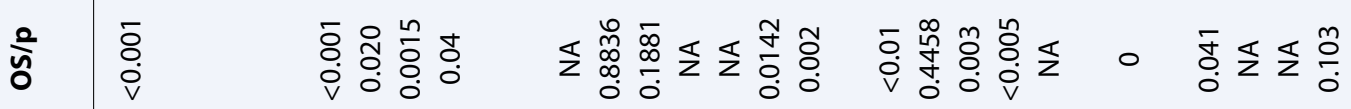

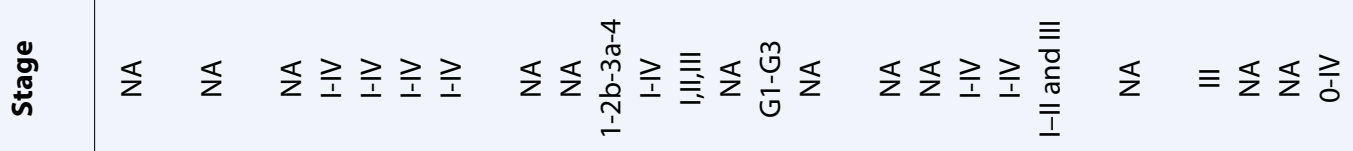

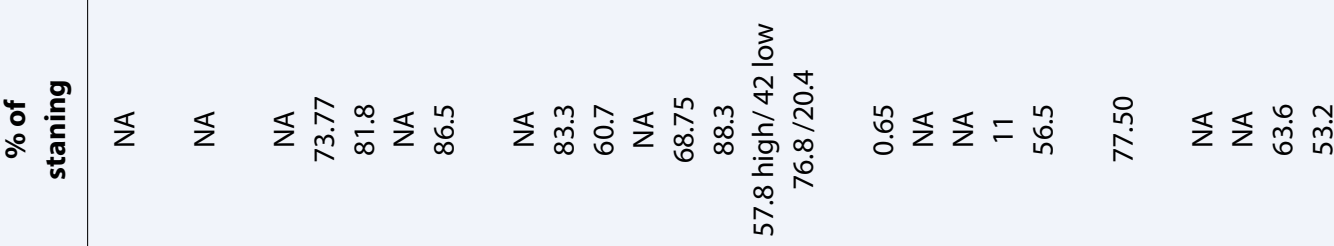

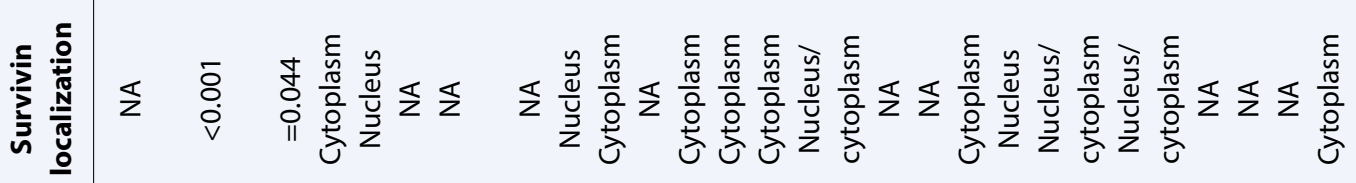

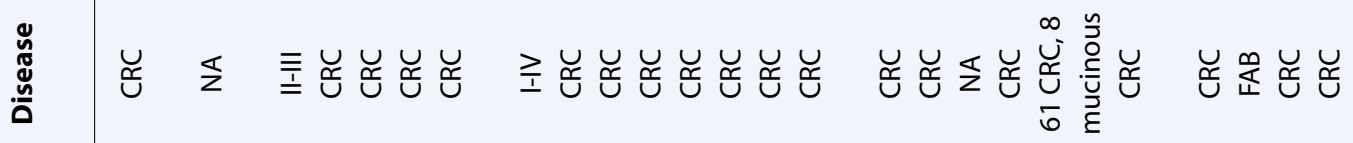

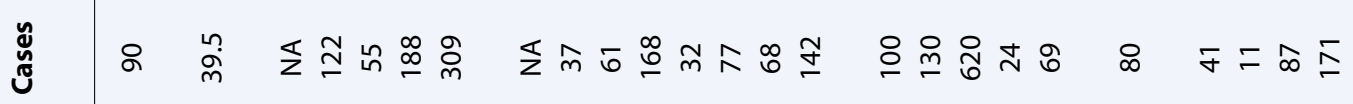

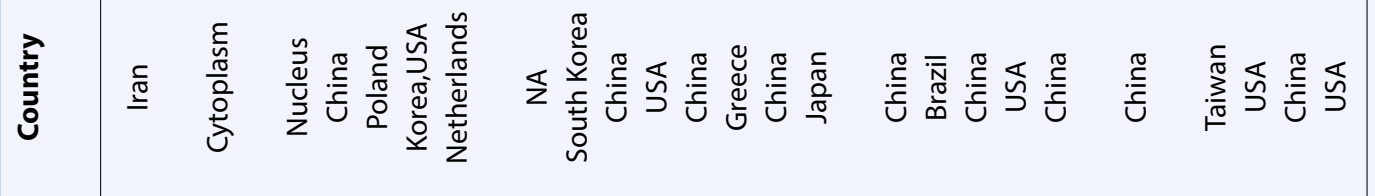

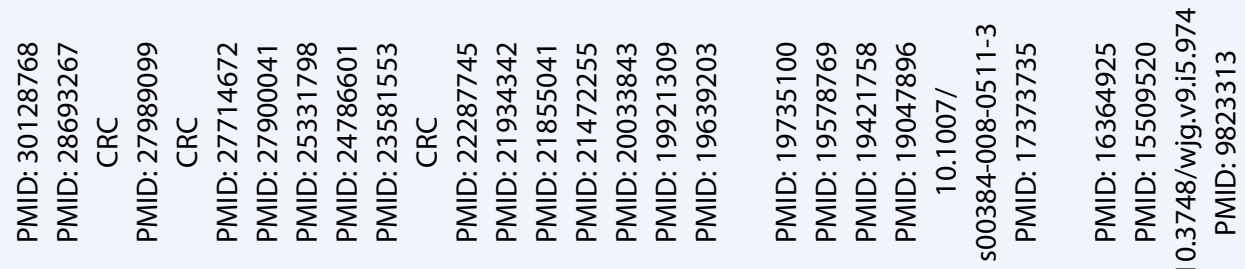

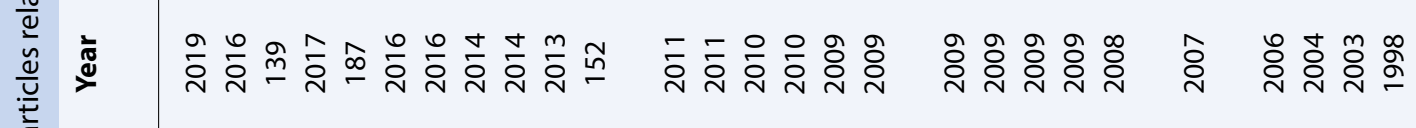
$\frac{\sqrt[4]{x}}{\frac{1}{\sqrt{5}}}$

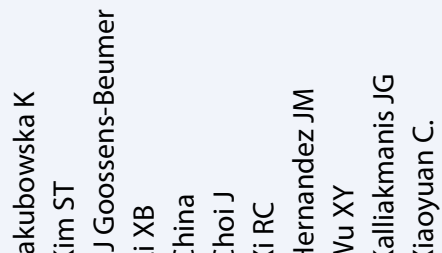

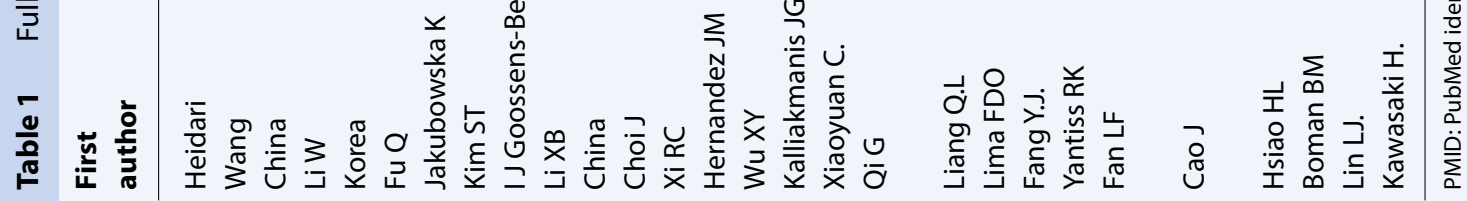




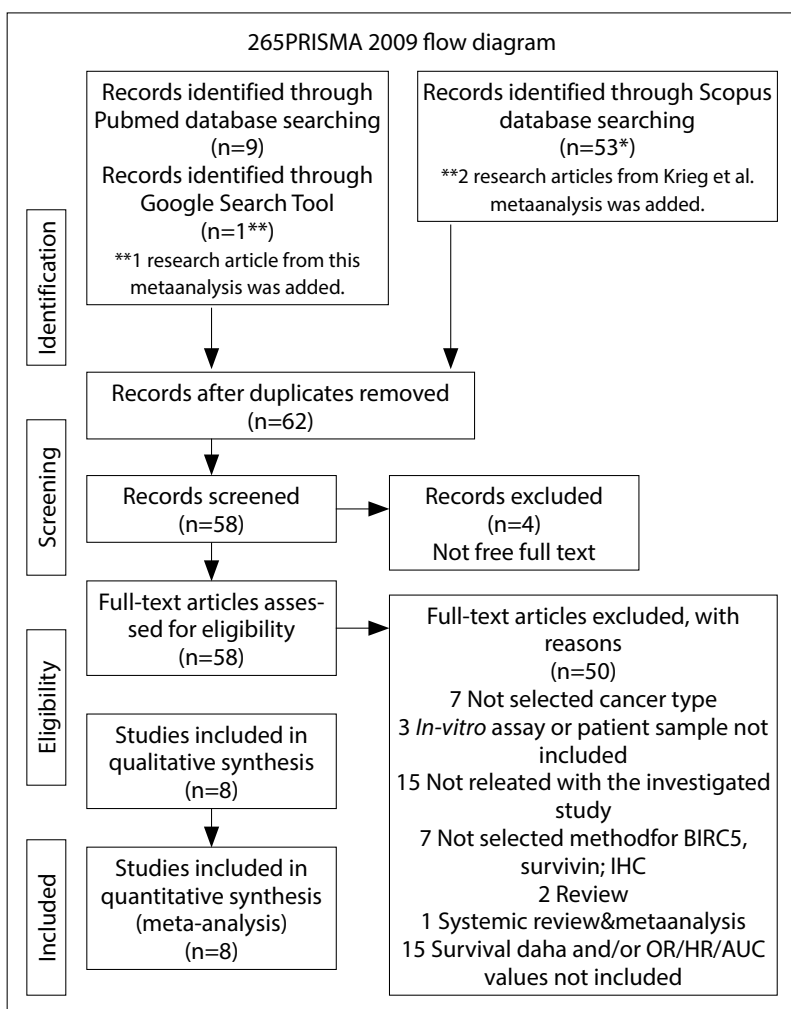

Fig. 1. Study selection for meta-analysis.

BIRC5: Baculoviral Inhibitor of apoptosis Repeat-Containing 5; IHC: Immunohistochemistry; OR: Odds ratio; HR: Hazard ratio; AUC: Area under the curve.

\section{Selection and Extraction Criteria}

The articles indicated the expression of survivin immunohistochemically and overall survival in CRC were selected. Articles associated with general staining were taken without considering the relationship with cytoplasmic and nuclear staining. After entering the keywords, the compliance of the articles obtained with the selection criteria was also confirmed from the article title and abstract. If there are relevant articles in the literature discussions of the included articles, they are also included in the study. From these articles with patient clinicopathological characteristics and overall survival data were selected. HR for overall survival was provided or could be calculated from the data presented were selected. Articles that provided sufficient data comparing the expression of survivin with clinicopathological data and that enabled us to calculate the HR. The publications in which a different analysis was made other than the immunohistochemistry analysis, the publications published in a different language other than English, and the publications without survival data were excluded. Articles were examined by two independent investigators; Aktas SH. and Akin-Bali DF. Extracted data were recorded by including first author's name, year of publication, PMID or DOI, region, number of cases, tumor stage, neoadjuvant therapy, cut off value, HR estimate, HR, and confidence interval (95\% CI).

\section{Statistical Analysis}

Statistical data analysis was performed in the comprehensive meta-analysis (version 3-trial edition) program. The HR was used to examine the relationship between CRC and survivin protein, for the relative weights of each research article. HR and 95\% confidence interval values and general summary HR were calculated and forest plot graph was obtained. HR $>1$ indicates that patients with survivin overexpression show a worse prognosis. Pooled estimates of HR were estimated by a random-effects model due to high between-study heterogeneity. Heterogeneity was assessed using Higgin's I2 statistic and Cochran's Q-test. Tausquared statistics as a part of the statistical analysis performed in the study and is the estimated variation between the effects for test accuracy observed in different studies. HR and 95\% CI values were calculated by Dersimonian and Laird random-effects model, assuming that the data consisted of different populations. In order to evaluate the risk of publication bias, funnel plots were obtained, including log Hazard ratio and standard error values on the $\mathrm{x}$ and $\mathrm{y}$ axes, respectively. $\mathrm{P}<0.05$ was accepted as the statistical significance level.

\section{Results}

\section{Relative Weights of Literature Studies and Forest Plot}

The distribution of the relative weights of the eight literature studies included in the meta-analysis according to the fixed and random effects model, and the calculated $\mathrm{HR}$ and $95 \%$ confidence interval values were obtained (Table 2 and Fig.2). The study that made the greatest contribution to meta-analysis is the study conducted by Fang et al. (2009). Heterogeneity was tested with the Cochran Q test statistic. As a matter of fact, the heterogeneity test statistic was obtained as $\mathrm{Q}=24.156$, $\mathrm{p}=0.004$ (Fig. 3). Therefore, heterogeneity was found between studies. In our study, heterogeneity was found $I^{2}: 62.74 \%$. Random effects model results were preferred since there was high heterogeneity between studies. According to the random-effects model, the effect size of the model was obtained as 1.446 (95\% CI: 1.103-1.897). 


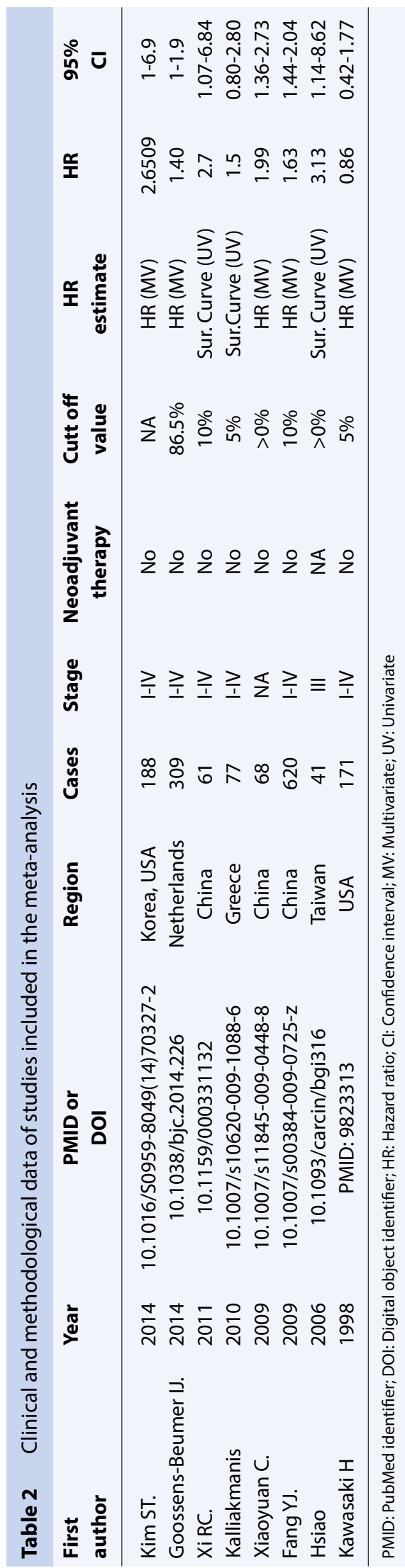

Funnel Plots a graphical representation of effect size and standard error. To determine the publication bias the bottom left of the funnel is analyzed. Negative or insignificant studies are listed on the lower left. If the lower left side is blank (asymmetric plot), it is stated as publication bias. According to the results of the analysis in the graph above, there is no publication bias for the literatures included in our study (Fig. 4). The symmetrical graph indicates the absence of publication bias. Our results show that overexpression of survivin in CRC is associated with poor prognosis $(\mathrm{HR}=1.446$; $\% 95 \mathrm{CI}$ : 1.103-1.897).

\section{Discussion}

The current meta analysis demonstrated that immunohistochemical staining of survivin in patients with CRC has a poor prognosis. To date, survivin has been the subject of many cancer researches. There are several main reasons for this situation, which have also been important in creating our current meta-analysis. Most importantly, survivin is not expressed in most normal differentiated tissues but is highly expressed in most cancer types.[5,6] Other important roles of survivin could be summarized as follows; it has important roles in the regulation of cell division and as an apoptosis inhibitor.[6] Survivin interacts with many different molecules in cancer, and it is stated that the important effects of these molecules are realized through survivin.[1315] Important findings regarding survivin function can be obtained from knock down studies that reveal the function of a gene. Studies have shown that knocking this gene stimulates apoptosis and inhibits cell invasion in colorectal adenocarcinoma cells.[16,17] In addition, there are studies showing that m-RNA over-expression and protein over-expression of survivin, which has important roles in cancer, increase cancer prognosis. [18] However, the prognostic value of survivin is not significant for all cancer types. For example, while its expression is expressed as an unfavorable prognostic indicator in esophageal and lung cancer, it may have prognostic value in breast, colorectal, pancreatic ductal adenocarcinoma, and hepatic carcinoma. [8]

Essentially, survivin has been subjected to some meta-analysis studies in terms of CRC prognosis due to these important features mentioned above. Huang et al.[12] conducted a meta-analysis study with data from 14 studies, 1784 CRC patients, and they obtained an output that matched the results of our current study. Krieg et al.[19] conducted a meta-analysis study with data from 15 studies and 1934 CRC patients. However, in the meta- 


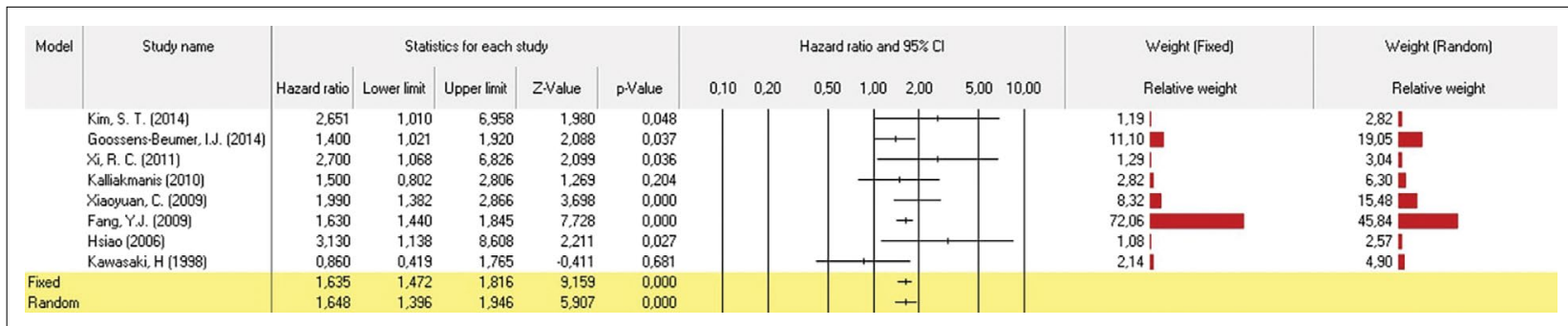

Fig. 2. Relative weights of studies included in the meta-analysis.

\begin{tabular}{|c|c|c|c|c|c|c|c|c|c|c|c|c|c|c|}
\hline \multirow{2}{*}{$\begin{array}{l}\text { Model } \\
\text { Model }\end{array}$} & \multirow[b]{2}{*}{$\begin{array}{l}\text { Number } \\
\text { Studies }\end{array}$} & \multicolumn{3}{|c|}{ Effect size and $95 \%$ interval } & \multicolumn{2}{|c|}{ Test of null [2-T ail] } & \multicolumn{4}{|c|}{ Heterogeneity } & \multicolumn{4}{|c|}{ Tau-squared } \\
\hline & & $\begin{array}{c}\text { Point } \\
\text { estimate }\end{array}$ & $\begin{array}{c}\text { Lower } \\
\text { limit }\end{array}$ & $\begin{array}{c}\text { Upper } \\
\text { limit }\end{array}$ & $Z$-value & P-value & Q-value & df (Q) & P-value & 1-squared & $\begin{array}{c}\text { Iau } \\
\text { Squared }\end{array}$ & $\begin{array}{c}\text { Standard } \\
\text { Error }\end{array}$ & Variance & Tau \\
\hline Fixed & 8 & 1.635 & 1,472 & 1.816 & 9.159 & 0.000 & 8.855 & 7 & 0.263 & 20.947 & 0.012 & 0.031 & 0.001 & 0.108 \\
\hline Random & 8 & 1.648 & 1,396 & 1.946 & 5,907 & 0.000 & & & & & & & & \\
\hline
\end{tabular}

Fig. 3. Heterogeneity of studies included in the meta-analysis.

analysis study of Krieg et al. included research articles using the real-time polymerase chain reaction method as well as the immunohistochemistry method of survivin.

Our current meta-analysis study was performed for 8 of 25 research articles in which survivin was stained immunohistochemically in CRC to date. The study of Kallikmanis et al. was extracted from Huang et al. metaanalysis and Krieg et al. metaanalysis. Hsiao et al. and Lin et al. study were extracted from Krieg et al. metaanalysis. Ponnelle, Qui, Sarela articles were not included although they were related to the overall survival in CRC and immunohistochemical staining of survivin from the Huang et al. meta-analysis study. [20-23] The reasons for this are; in the article of Lee et al., the relationship of survivin with overall survival was evaluated according to the low and high amount of survivin. In the Ponnelle et al. and Qi et al. articles, the relationship between nuclear/cytoplasmic localization of survivin and overall survival was evaluated. In the article of Sarela et al. immunohistochemical analysis was not performed, the polymerase chain reaction was performed from paraffin tissues.

Eight articles define the criteria for the meta-analysis we performed; survival data HR, HR estimate, 95\% CI data. Immunohistochemical method was chosen for meta-analysis. Thus, it was aimed to create relatively less heterogeneity in the meta-analysis of the articles, which were basically carried out using a single technique.

Investigating the articles that we have meta-analyzed, the article of Fang et al.[24] appears to be made the greatest contribution to the meta-analysis. Multivariate analyzes of the study conducted by Fang et al. from a total of 602 CRC paraffin tissue samples showed that survivin, MMP7 and TROP2 are significant predictors for lower patient survival.

The contribution to the meta-analysis of the 2009 article by Fang et al. was determined as $45.84 \%$. After this study, Goossens Beumer et al. made the highest contribution in the study they carried out in 2014 . The contribution of the research to the meta-analysis was 19.05\% ( $\mathrm{HR}=1.63 \mathrm{CI} \% 95$ 1.440-1.845 $\mathrm{p}<0.001$; $\mathrm{HR}=1.40$, CI \% 95 1.021-1.920 $\mathrm{p}<0.037)$.

\section{Conclusion}

Our meta-analysis performed from a total of eight articles and 535 CRC patients showed that expression of survivin was significantly associated with overall survival in CRC patients and can serve as a prognostic marker in CRC patients.

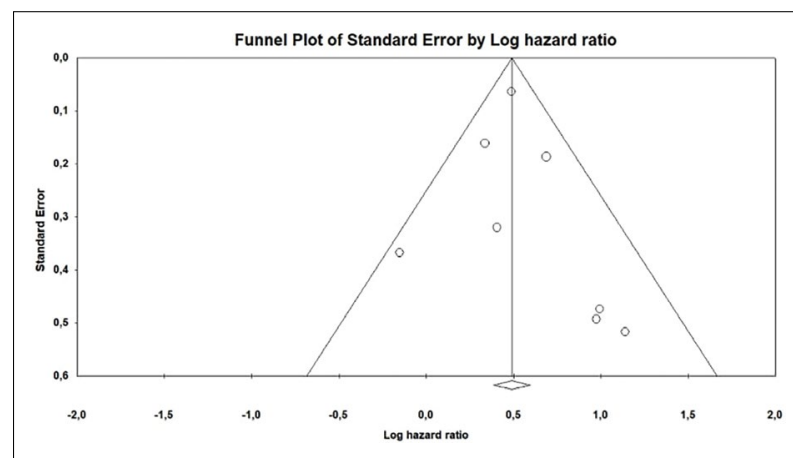

Fig. 4. Funnel plot of studies included in the meta-analysis to visualize a potential publication bias. 
Peer-review: Externally peer-reviewed.

Conflict of Interest: All authors declared no conflict of interest.

Ethics Committee Approval: Ethical approval is not applicable, because this article does not contain any studies with human or animal subjects. The analyzed data are publicly available.

Financial Support: This study has received no financial support.

Authorship contributions: Concept - S.H.A.; Design S.H.A., O.Y.; Supervision - S.H.A., D.F.A.B.; Funding - None; Materials - None; Data collection and/or processing - B.E.; Data analysis and/or interpretation - S.H.A., B.E., D.F.A.B.; Literature search - S.H.A., D.F.A.B., O.Y.; Writing - S.H.A., B.E.; Critical review - S.H.A., D.F.A.B., O.Y.

\section{References}

1. Sung H, Ferlay J, Siegel RL, Laversanne M, Soerjomataram I, Jemal A, et al. Global Cancer Statistics 2020: GLOBOCAN estimates of incidence and mortality worldwide for 36 cancers in 185 countries. CA Cancer J Clin 2021;71(3):209-49.

2. Hoff PM, Cassidy J, Schmoll HJ. The evolution of fluoropyrimidine therapy: from intravenous to oral. Oncologist 2001;6 (Suppl 4):3-11.

3. Crook NE, Clem RJ, Miller LK. An apoptosis-inhibiting baculovirus gene with a zinc finger-like motif. J Virol 1993;67(4):2168-74.

4. Ambrosini G, Adida C, Altieri DC. A novel anti-apoptosis gene, survivin, expressed in cancer and lymphoma. Nat Med 1997;3(8):917-21.

5. Jaiswal PK, Goel A, Mittal RD. Survivin: A molecular biomarker in cancer. Indian J Med Res 2015;141(4):389-97.

6. Garg H, Suri P, Gupta JC, Talwar GP, Dubey S. Survivin: a unique target for tumor therapy. Cancer Cell Int 2016;16:49.

7. Altieri DC. The molecular basis and potential role of survivin in cancer diagnosis and therapy. Trends Mol Med 2001;7(12):542-7.

8. Liu JL, Gao W, Kang QM, Zhang XJ, Yang SG. Prognostic value of survivin in patients with gastric cancer: a systematic review with meta-analysis. Plos One 2013;8(8):e71930.

9. Amur S, LaVange L, Zineh I, Buckman-Garner S, Woodcock J. Biomarker qualification: toward a multiple stakeholder framework for biomarker development, regulatory acceptance, and utilization. Clin Pharmacol Ther 2015;98(1):34-46.

10. Oh HH, Joo YE. Novel biomarkers for the diagnosis and prognosis of colorectal cancer. Intest Res 2020;18(2):168-83.

11. Xu L, Zhou X, Xu L, Yin R. Survivin rs9904341 (G>C) polymorphism contributes to cancer risk: an updated meta-analysis of 26 studies. Tumour Biol 2014;35(2):1661-9.

12. Huang YJ, Qi WX, He AN, Sun YJ, Shen Z, Yao Y. The prognostic value of survivin expression in patients with colorectal carcinoma: a meta-analysis. Jpn J Clin Oncol 2013;43(10):988-95.

13. Luo C, Yuan R, Chen L, Zhou W, Shen W, Qiu Y, et al. TAB3 upregulates Survivin expression to promote colorectal cancer invasion and metastasis by binding to the TAK1-TRAF6 complex. Oncotarget 2017;8(63):106565-76.

14. Dong D, Jiang W, Lei J, Chen L, Liu X, Ge J, et al. Ubiquitin-like protein FAT10 promotes bladder cancer progression by stabilizing survivin. Oncotarget. 2016 Dec 6;7(49):81463-73.

15. Lin Y, Zhong H, Sun B, Peng Y, Lu F, Chen M, et al. USP22 promotes proliferation in renal cell carcinoma by stabilizing survivin. Oncol Lett 2020;20(5):246.

16. Qi G, Kudo Y, Tang B, Liu T, Jin S, Liu J, et al. PARP6 acts as a tumor suppressor via downregulating Survivin expression in colorectal cancer. Oncotarget 2016;7(14):18812-24.

17. Wang H, Li S, Luo X, Song Z, Long X, Zhu X. Knockdown of PARP6 or survivin promotes cell apoptosis and inhibits cell invasion of colorectal adenocarcinoma cells. Oncol Rep 2017;37(4):2245-51.

18. Jakubowska K, Pryczynicz A, Dymicka-Piekarska V, Famulski W, Guzińska-Ustymowicz K. Immunohistochemical expression and serum level of survivin protein in colorectal cancer patients. Oncol Lett 2016;12(5):3591-7.

19. Krieg A, Werner TA, Verde PE, Stoecklein NH, Knoefel WT. Prognostic and clinicopathological significance of survivin in colorectal cancer: a meta-analysis. PLos One 2013;8(6):e65338.

20. Lee YY, Yu CP, Lin CK, Nieh S, Hsu KF, Chiang H, et al. Expression of survivin and cortactin in colorectal adenocarcinoma: association with clinicopathological parameters. Dis Markers 2009;26(1):9-18.

21. Ponnelle T, Chapusot C, Martin L, Bouvier AM, Plenchette S, Faivre J, et al. Cellular localisation of survivin: impact on the prognosis in colorectal cancer. J Cancer Res Clin Oncol 2005;131(8):504-10.

22. Qi G, Tuncel H, Aoki E, Tanaka S, Oka S, Kaneko I, et al. Intracellular localization of survivin determines biological behavior in colorectal cancer. Oncol Rep 2009;22(3):557-62.

23. Sarela AI, Macadam RC, Farmery SM, Markham AF, Guillou PJ. Expression of the antiapoptosis gene, survivin, predicts death from recurrent colorectal carcinoma. Gut 2000;46(5):645-50.

24. Fang YJ, Lu ZH, Wang GQ, Pan ZZ, Zhou ZW, Yun JP, et al. Elevated expressions of MMP7, TROP2, and survivin are associated with survival, disease recurrence, and liver metastasis of colon cancer. Int J Colorectal Dis 2009;24(8):875-84. 


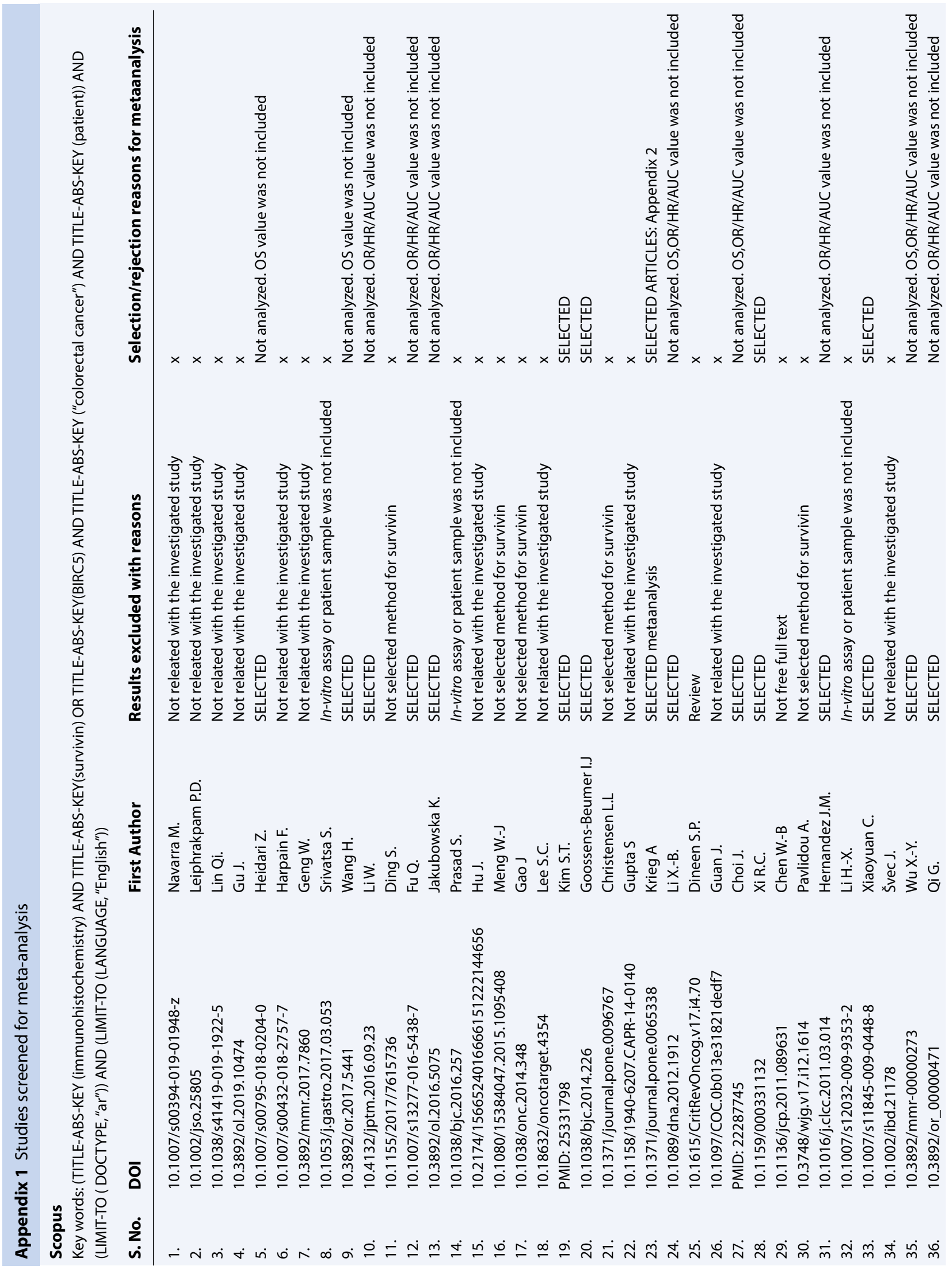




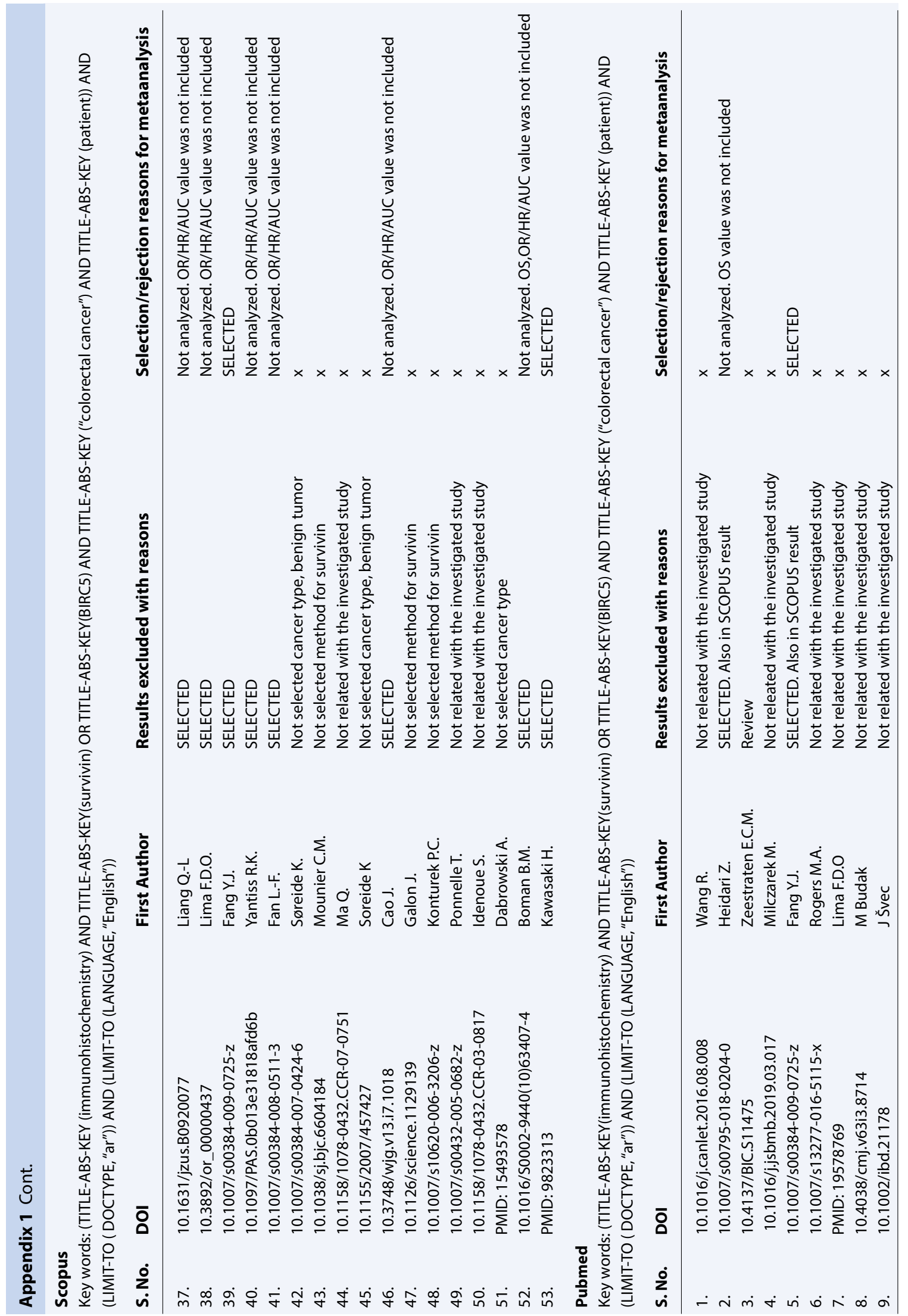




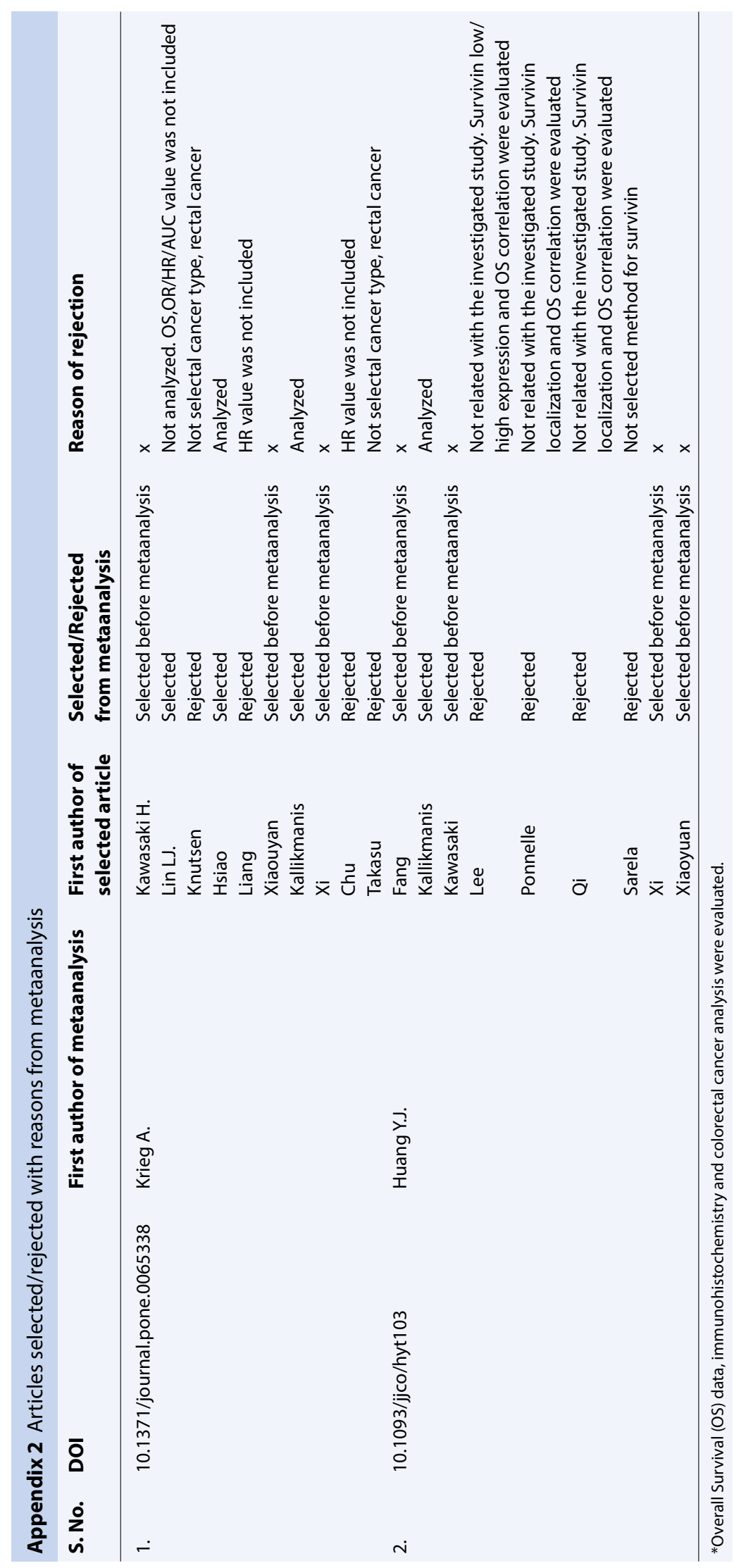

